\title{
El pensamiento crítico como una herramienta de desarrollo de liderazgo
}

\section{Critical thinking as a leadership development tool}

Ing. María Auxiliadora Guerrero Bejarano, MBA

Universidad Internacional del Ecuador

Ing. Viviana Vanesa Medina Vergara, MBA

Universidad Internacional del Ecuador

Autores para correspondencia: maguerrero@uide.edu.ec; vimedinave@uide.edu.ec

Fecha de recepción: 17 de Enero de 2016 - Fecha de aceptación: 15 de Marzo de 2016

\section{Resumen}

Este estudio tiene como objetivo principal resaltar la importancia del pensamiento crítico desde su concepto hasta la aplicabilidad que se le puede dar en la toma de decisiones, el uso de este tipo de pensamiento se presupone debe enseñarse desde la educación primaria, pero realmente no todas las personas pueden tener un verdadero dominio sobre él, puede llegar a ser una fuente de ventajas para quienes logran este objetivo y logran actuar de acuerdo a este tipo de razonamiento, lo que permitirá en algunos casos obtener mejores resultados en la búsqueda de convertirse en líderes.

Palabras claves: pensamiento crítico; razonamiento; liderazgo

\begin{abstract}
This study's main objective is to highlight the importance of critical thinking from concept to apply than can be given in decision -making, the use of this type of thinking is assumed to be taught from primary school, but not really everyone can have a real grip on it, can become a source of benefits for those who fail to achieve this objective and to act according to this reasoning, allowing in some cases better results in the pursuit of becoming leaders.
\end{abstract}

Key words: critical thinking; thinking; leadership 


\section{Introducción}

Cuando se intenta definir criterios sobre diferentes aspectos que son parte de actividades que podríamos realizar día a día, como liderar equipos de trabajo por ejemplo, se encontrarían actividades que se desarrollan con regularidad, pero que no son interiorizadas como procesos que pueden permitir obtener los mejores resultados de estas acciones; pensar críticamente es una acción que podría ser bastante más común de lo que parecería, pero que exige una disciplina que no siempre es concientizada en el diario vivir. Para D`Alessio (2010) pensar es una actividad del cerebro que podría eventualmente ser expresada por intermedio de actos, el habla o la escritura, estos reflejan el potencial de las capacidades del ser humano, existiendo dimensiones cognitivas, conductuales y afectivas. El pensamiento es un proceso, lo que implica que posee elementos que son transformados para obtener productos; en este proceso los insumos que recibe el cerebro se obtienen a través de los cinco sentidos, siendo los principales proveedores el sentido de la vista y del oído; D’Alessio define analógicamente al cerebro como una caja negra dónde se desarrolla el proceso del pensamiento.

Todos los sentidos aportarían a este proceso, que podría ser considerado algo complejo, pero el entrenamiento, la experiencia, el entorno, la sociedad entre otros elementos favorecen el pensamiento; una actividad que por mucho años fue parte de la enseñanza, sobre todo en los niveles más básicos de la educación de los individuos, podría no ayudar a desarrollar adecuadamente el pensamiento, sobretodo el crítico, está es la enseñanza memorística que impide que el individuo desarrolle sus propios concepto o simplemente se encuentre abierto a nuevos conceptos o ideas (Kirby \& Goodpaster, 2002); tradicionalmente era la práctica de enseñanza más común. Hoy en día aunque el pensamiento crítico y el desarrollo de criterios son parte de la enseñanza desde los niveles secundarios, podríamos notar errores en el manejo de los conceptos de estas actividades. Entendiendo entoces que el pensamiento crítico exige elementos como la disciplina, la capacidad de las personas para auto dirigirse y dominio sobre las habilidades y destrezas del individuo que intenta convertirse o llegar a ser un pensador crítico.

Para D’Alessio, la persona crítica es la que ha logrado dominar ciertas habilidades intelectuales y destrezas teniendo intereses egoístas en niveles débiles o sesgados, más bien tiene un sentido fuerte y completo de imparcialidad en su forma de analizar las cosas. Entendiendo que el lenguaje (discurso, escritura, seña, para lenguaje y mímica), las imágenes (planos gráficos y símbolos), el arte (dibujo, puntura, escultura, modelaje, arquitectura, música, danza) y las matemáticas son los medios de comunicación más conocidos que permiten la práctica del pensamiento crítico y el desarrollo de actividades como la observancia crítica que se basa en la recepción de imágenes a través del sentido competente (la vista) pero que sería complementa por los demás sentidos.

Existen barreras y errores comunes que podrían afectar el pensamiento crítico o el desarrollo del mismo, se encuentran factores como la enculturación que implicaría una afectación del pensamiento a partir de valores, del contexto en el que se ha desarrollado el pensador, se esperaría que con el paso del tiempo y la práctica de este tipo de pensamiento, el individuo pudiera hacer un mejor uso del mismo impidiendo que este tipo de problemas afectara su manejo del proceso. Se encuentran otras barreras como la defensa del ego, la influencia 
emocional, expectativas propias, el concepto de sí mismo, que también afectan el desarrollo del pensamiento.

Dentro de la influencia emocional se encuentran por ejemplo la ira, la pasión y la depresión que pueden generar problemas a la hora de analizar críticamente algo. Se debe destacar la disonancia cognitiva, que también es una barrera para el desarrollo del pensamiento, es el esfuerzo por una consistencia cognitiva que se refiere a una armonía entre los pensamientos y conductas, es decir pensar de una forma y actuar de manera diferente, esta discordancia puede producir como consecuencia tensión psicológica e incomodidad. El estrés es otra barrera para el pensamiento crítico, este se define como la excesiva demanda sobre el cuerpo o la mente que produce una presión física o psicológica, los individuos que se encuentran bajo estrés generalmente disminuyen su habilidad para percibir soluciones alternativas a los problemas, pueden ver afectada su capacidad de buscar información relevante para la toma de decisiones y suelen no prestar atención a las consecuencias a largo plazo de las decisiones tomadas (D’Alessio, 2010)

Actualmente el desarrollo del pensamiento crítico se ha convertido en un tema de interés de acuerdo a Bailin, Coombs y Daniels (1999 a) debido a su importancia como herramienta para la generación de nuevos conceptos y la generación de nuevas formas para hacer las cosas, el pensamiento crítico permitiría al pensador desaprender para volver a aprender sobre conceptos que podrían evolucionar.

En este punto se podría inferir en base a los conceptos revisados que el pensamiento crítico se podría desarrollar cumpliendo rutinas que fortalezcan las costumbres adecuadas para que los individuos se conviertan en pensadores críticos, un pensador crítico podría tener una ventaja sobre los demás individuos a la hora de querer desarrollar habilidades de liderazgo lo que podría permitirle obtener mejores resultados en procesos de toma de decisión. También se podría suponer que un individuo que posee habilidades de pensador crítico, tendría una mayor probabilidad de poder manejar sus emociones y aumentar sus niveles de inteligencia emocional, incrementando sus capacidades cognitivas y de análisis de situaciones, sabiendo que la inteligencia emocional permite a las personas el manejo de sus emociones que implica conocerse, es decir estar consciente de qué puede afectar el normal desarrollo de cada persona, habiendo identificado esos factores, manejarlos para que en lugar de recibir una afectación negativa de ellos poder sacar lo mejor de cualquier situación, también implica ser empáticos con los demás para finalmente tener un mejor manejo y desarrollo con otras personas lo que tendría como finalidad el desarrollo de relaciones positivas con los demás individuos, que como consecuencia produciría mejores resultados en el manejo de equipo, obtención de resultados y desarrollo de habilidades como líder (Goleman, 1998).

El pensamiento crítico también podría ser considerado un facilitador en la toma de decisiones dentro de situaciones que presentan dilemas éticos, puesto que podría permitir al tomador de decisiones hacer análisis más complejos sobre los distintos contextos que hacen parte del problema que se ha presentado, si consideramos que en lo que respecta a la ética, también se encuentran situaciones en las que los contextos podrían afectar las realidades que hacen parte de esas situaciones sobre las que se deben tomar decisiones. El manejo de conceptos crítico sería un 
factor esencial para la toma de decisiones de los futuros líderes, para Elder, L y Paúl R (1999) los conceptos se encuentran en todas las partes y hacen parte del proceso de volver real las cosas, debido a que solamente luego de conceptualizar las cosas se puede realmente a pensar en ellas.

\section{Conclusión}

Los líderes en general se enfrentan todos los días a situaciones diferentes que los obligan a tomar decisiones, debido a esta realidad se comprendería la necesidad de éstos a desarrollar habilidades como el pensamiento crítico que le permitiría desmenuzar cada situación y definir acciones esperando obtener los mejores resultados. Pensar críticamente obligaría al líder a abrir su mente, estar consciente de su probabilidad de error, de tal forma que pudiera aprovechar de mejor forma los aportes que serían parte de las posibles contribuciones de los diferentes miembros de sus equipos; esta apertura de mente también ayudaría a desarrollar otros tipos de habilidades como la adaptación y la generación de ideas y estrategias, creatividad y la capacidad cognitiva, es decir el pensador crítico tendría una mejor predisposición al aprendizaje, a generar nuevas formas de hacer las cosas en una búsqueda por obtener los mejores resultados de cada situación. La inteligencia emocional también se vería afectada por el pensamiento crítico, debido a que esa capacidad de análisis que desarrolla el pensador crítico podría evitar que el líder se enfoque únicamente en las emociones y se pueda perder en situaciones en las que dominen características mucho más emocionales pudiendo perjudicar al tomador de decisiones a la hora de definir cursos de acción.

\section{Bibliografía}

Bailin, Case, Coombs, \& Daniels (1999a). Common misconceptions of critical thinking. Journal Of Curriculum Studies, 31(3), 269-283.

D’Alessio, F. (2009), Liderazgo y atributos gerenciales. Una visión global y estratégica. México D.F., México: Pearson

Elder, L. \& Paul. R. (1999). Critical thinking: Teaching students to seek the logic of things. Journal of developmental education, 23(1), 34-35.

Goleman, Daniel (1998) ¿Qué hace a un líder? Harvard Business Review, 76(6) 93-102 Kirby, G.R \& Goodpaster, J.R. (2002) Thinking (3rd Ed.) Upper Saddle River, Prentice Hall 